\title{
Pain Anxiety and its Association with Pain Congruence Trajectories During the Cold Pressor Task
}

Citation for published version (APA):

Clark, S. M., Cano, A., Goubert, L., Vlaeyen, J. W. S., Wurm, L. H., \& Corley, A. M. (2017). Pain Anxiety and its Association with Pain Congruence Trajectories During the Cold Pressor Task. The Journal of Pain, 18(4), 396-404. https://doi.org/10.1016/j.jpain.2016.11.013

Document status and date:

Published: 01/04/2017

DOI:

10.1016/j.jpain.2016.11.013

Document Version:

Publisher's PDF, also known as Version of record

Document license:

Taverne

Please check the document version of this publication:

- A submitted manuscript is the version of the article upon submission and before peer-review. There can be important differences between the submitted version and the official published version of record.

People interested in the research are advised to contact the author for the final version of the publication, or visit the DOI to the publisher's website.

- The final author version and the galley proof are versions of the publication after peer review.

- The final published version features the final layout of the paper including the volume, issue and page numbers.

Link to publication

\footnotetext{
General rights rights.

- You may freely distribute the URL identifying the publication in the public portal. please follow below link for the End User Agreement:

www.umlib.nl/taverne-license

Take down policy

If you believe that this document breaches copyright please contact us at:

repository@maastrichtuniversity.nl

providing details and we will investigate your claim.
}

Copyright and moral rights for the publications made accessible in the public portal are retained by the authors and/or other copyright owners and it is a condition of accessing publications that users recognise and abide by the legal requirements associated with these

- Users may download and print one copy of any publication from the public portal for the purpose of private study or research.

- You may not further distribute the material or use it for any profit-making activity or commercial gain

If the publication is distributed under the terms of Article $25 \mathrm{fa}$ of the Dutch Copyright Act, indicated by the "Taverne" license above, 


\title{
Pain Anxiety and Its Association With Pain Congruence Trajectories During the Cold Pressor Task
}

\author{
Shannon M. Clark, ${ }^{*}$ Annmarie Cano, ${ }^{*}$ Liesbet Goubert, ${ }^{\dagger}$ Johan W. S. Vlaeyen, ${ }^{\ddagger}$ \\ Lee H. Wurm, ${ }^{*}$ and Angelia M. Corley* \\ *Wayne State University, Detroit, Michigan. \\ ${ }^{\dagger}$ Ghent University, Ghent, Belgium. \\ ${ }^{\ddagger} K U$ Leuven, University of Leuven, Leuven, Belgium.
}

\begin{abstract}
Incongruence of pain severity ratings among people experiencing pain and their observers has been linked to psychological distress. Previous studies have measured pain rating congruence through static self-report, involving a single rating of pain; however, this method does not capture changes in ratings over time. The present study examined the extent to which partners were congruent on multiple ratings of a participants' pain severity during the cold pressor task. Furthermore, 2 components of pain anxiety-pain catastrophizing and perceived threat-were examined as predictors of pain congruence. Undergraduate couples in a romantic relationship $(N=127$ dyads) participated in this study. Both partners completed measures of pain catastrophizing and perceived threat before randomization to their cold pressor participant or observer roles. Participants and observers rated the participant's pain in writing several times over the course of the task. On average, observers rated participants' pain as less severe than participants' rated their own pain. In addition, congruence between partners increased over time because of observers' ratings becoming more similar to participant's ratings. Finally, pain catastrophizing and perceived threat independently and jointly influenced the degree to which partners similarly rated the participant's pain.

Perspective: This article presents a novel application of the cold pressor task to show that pain rating congruence among romantic partners changes over time. These findings indicate that pain congruence is not static and is subject to pain anxiety in both partners.
\end{abstract}

(c) 2016 by the American Pain Society

Key words: Pain, congruence, anxiety, threat, catastrophizing, romantic relationships, couples.

$\mathbf{P}$ ain rating congruence research has consistently reported that spouses and physicians underestimate the severity and effect of chronic pain..$^{2-4,32,34}$ In the context of empathy models, pain congruence is an indicator of an observer's "sense of knowing" about another's pain. ${ }^{13}$ This sense of knowing is hypothesized to be a function of characteristics of the observer as well as the person with pain. However, the existing literature is limited in its the ability to identify key characteristics that affect congruence in real time. First, congruence research has relied on static reports (ie, a sin-

\footnotetext{
Received June 29, 2016; Revised November 15, 2016; Accepted November 22, 2016.

The authors have no conflicts of interest to declare.

Address reprint requests to Shannon M. Clark, MS, MA, Department of Psychology, Wayne State University, 5057 Woodward Ave, 7th Floor, Detroit, MI 48202. E-mail: shannon.clark4@wayne.edu

$1526-5900 / \$ 36.00$

(c) 2016 by the American Pain Society

http://dx.doi.org/10.1016/j.jpain.2016.11.013
}

gle retrospective report often in the absence of observation). It is unlikely that this type of assessment accurately reflects the congruence process. Second, a limited number of characteristics have been examined with respect to congruence (eg, gender, mood, and marital satisfaction). ${ }^{2-4,29}$ To address these gaps, the current study assessed pain rating congruence over the course of a painful task and examined pain anxiety variables as characteristics that may affect congruence.

Pain anxiety variables may be key characteristics that alter the course of pain congruence, especially because of the theoretical and empirical work showing the significance of pain anxiety to the pain experience. $9,21,22,33,40$ Two indicators of pain anxiety, pain catastrophizing and perceived threat, were examined in the current study. Pain catastrophizing is generalized worry associated with pain and is related to increased pain intensity. ${ }^{16,38,40}$ Perceived threat is one's appraisal about the threatening nature of a pain-eliciting task or activity. ${ }^{24}$ Yet, little is 
known about how pain anxiety in each person may correlated with congruence. Following the communal coping model of pain, ${ }^{35,37,38}$ pain catastrophizing and perceived threat reported by individuals in pain may be related to greater pain congruence for at least 2 reasons. First, both may result in greater pain behavior expression during the task, which could assist observers in estimating their partner's pain. Second, pain anxiety in participants may prime observers to expect, through previous knowledge about the partner or observations made during the task, that the participant is in greater pain. A "sense of knowing" may also depend on the observer's pain anxiety. ${ }^{13}$ For instance, anxiety in observers may reduce pain congruence in the current study. Observers who are generally worried about their partners' pain, or who are fearful about their partners undergoing a painful task, may experience distress themselves. $4,12,22$ To regulate emotion, observers may defensively distance themselves from their partner's pain, ${ }^{19,31}$ which may result in greater incongruence as they tune out their partner's pain signals or engage in other avoidant behaviors.

The aims of the current study were to examine 1) trajectories of pain congruence during a painful task, and 2) the extent to which these trajectories were influenced by pain anxiety in observers and people experiencing pain. On the basis of the congruence literature, participants completing the cold pressor task were expected to provide higher pain ratings than those provided by their observing partners. It was expected that both partners' pain ratings would become more congruent over time, because the observing partner would develop a greater sense of knowing by viewing their partner's behaviors over time. We expected a curvilinear trajectory in congruence on the basis of previous research with individuals undergoing the cold pressor task. ${ }^{6,26}$ Participant and observer pain anxiety variables were expected to relate to congruence, albeit in different directions. Little is known regarding the extent to which these indicators of pain anxiety contribute to congruence. This lack of knowledge hampers efforts to identify individual and observer characteristics that affect "sense of knowing" and the attendant responses that can enhance or inhibit pain coping.

\section{Methods}

\section{Participants}

This study was approved by the university's institutional review board and participants and their partners provided informed consent. Participants were 268 individuals (134 romantic dyads) who were enrolled at Wayne State University or were significant others of an undergraduate student. Participants were recruited for a larger study via an online registration. ${ }^{6}$ Student participants were eligible to receive extra credit in their psychology courses for participation. Partners who were not enrolled in courses did not receive compensation. To minimize risk, participants were not eligible to undergo the cold pressor task if they reported a blood circulation problem (eg, diabetes or Raynaud syndrome). Before arrival, participants were screened via telephone and not recruited if they reported a chronic pain condition.

To differentiate between roles assigned to partners, the term "participant" will refer to individuals who completed the cold pressor task, and "observer" will refer to individuals who watched their partner undergo the task via a live video feed playing in an adjacent room. Approximately $52 \%(n=70)$ of the couples had female participants complete the cold pressor task, and approximately $55 \%(n=73)$ of the couples had a male observer. Because of the small number of same-sex couples enrolled in the study (7 of 134), these gender percentages are not complementary to each other. The average length of time that the couples reported being together was 26.94 months $(S D=25.78)$. See Table 1 for additional demographic information.

\section{Measures}

\section{Demographic Information}

Participants and observers reported gender, race, ethnicity, age, relationship status, relationship length, highest education level obtained, and employment status for descriptive purposes.

\section{Potential Covariates}

At baseline, participants and observers completed the Couples Satisfaction Index, a measure of relationship satisfaction, ${ }^{36}$ and a subscale of the Interpersonal Reactivity Scale that measures empathic concern. ${ }^{7}$ These

Table 1. Sample Demographic Characteristics

\begin{tabular}{|c|c|c|c|c|}
\hline \multirow[b]{2}{*}{ VARIABLE } & \multicolumn{2}{|c|}{ Participant } & \multicolumn{2}{|c|}{ OBSERVER } \\
\hline & $N$ & $\%$ & $N$ & $\%$ \\
\hline \multicolumn{5}{|l|}{ Gender } \\
\hline Male & 64 & 47.8 & 73 & 54.5 \\
\hline Female & 70 & 52.2 & 61 & 45.5 \\
\hline \multicolumn{5}{|l|}{ Race/ethnicity } \\
\hline Caucasian & 68 & 50.7 & 64 & 47.8 \\
\hline African American & 38 & 28.4 & 38 & 28.4 \\
\hline Asian American & 25 & 18.7 & 25 & 18.7 \\
\hline Native American & 1 & .7 & 0 & - \\
\hline Pacific Islander & 0 & - & 1 & .7 \\
\hline Middle Eastern & 23 & 17.2 & 10 & 7.5 \\
\hline Hispanic/Latino & 10 & 7.5 & 19 & 14.2 \\
\hline \multicolumn{5}{|l|}{ Education } \\
\hline College experience & 107 & 81.1 & 108 & 80.6 \\
\hline $\begin{array}{l}\text { High school diploma (no college } \\
\text { experience) }\end{array}$ & 21 & 79.8 & 20 & 14.9 \\
\hline \multirow[t]{2}{*}{ Graduate school experience } & 3 & 2.2 & 6 & 4.3 \\
\hline & MEAN & $S D$ & MEAN & $S D$ \\
\hline Age & 22.89 & 6.11 & 22.73 & 5.72 \\
\hline Relationship Satisfaction & 5.56 & 2.17 & 5.50 & 2.19 \\
\hline Empathic Concern & 20.37 & 4.14 & 20.13 & 4.52 \\
\hline Perceived Threat Prior to Task & 11.08 & 9.33 & 11.69 & 9.01 \\
\hline Baseline Pain Catastrophizing & 17.78 & 10.24 & 18.55 & 9.92 \\
\hline
\end{tabular}

NOTE. Higher scores on relationship satisfaction and empathic concern indicate increased levels of variables reported. 
scales were included for descriptive purposes and as potential covariates because these variables could conceivably be related to congruence.

\section{Pain Catastrophizing}

The Pain Catastrophizing Scale (PCS), ${ }^{36}$ a 13-item measure, was administered to both partners to provide a baseline pain catastrophizing score. The PCS measures the extent to which an individual, in general, has a tendency to ruminate, magnify, of feel helpless about pain. Scores on this measure range from 0 to 52 , and items include statements like, "I worry all the time about whether the pain will end.," and "I become afraid that the pain may get worse."

\section{Perceived Threat}

Participants and observers completed 4 questions aimed to assess the extent to which both partners felt threatened and fearful about the task (eg, "How anxious or tense are you about doing the cold water task?"). Observers received questions that emphasized that they would be reporting on their own expected threat regarding their partner who was about to complete the task (eg, "Right now, how anxious or tense are YOU about your partner doing the cold water task?"). The measure used an 11-point Likert scale (0 = "Not at all", $10=$ "Very much") and is adapted from a state threat measure in other studies investigating pain rating congruence between parents and children. ${ }^{14,15,39}$ The 4 items yielded a total score representing the participant's or observer's perceived threat of pain. Average scores on measures of relationship satisfaction, empathic concern, baseline pain catastrophizing, and perceived threat before the task, for participants and observers, are listed in Table 1.

\section{Pain Intensity}

Pain intensity was measured during the cold pressor task while the participant had their hand submerged and the observer watched from an adjacent room. Participants and observers rated levels of pain intensity on an 11 -point scale. Responses were numeric with 0 representing "no pain" and 10 representing "extreme pain." When a tone alerted them to do so, they were asked to record in writing pain intensity at that current moment. Tones were sounded every 10 seconds for the first 40 seconds and every 20 seconds thereafter. Pain congruence was calculated by subtracting the observer pain rating score from the participant pain rating score at each interval. Thus, each dyad had at most 8 "pain difference" or congruence scores. Average ratings of pain intensity for participants and observers are provided in Table 2.

\section{Study Procedures}

Ethical approval was obtained by the Wayne State University institutional review board. The study was advertised on the Psychology Department's student subject pool Web site and potential participants were told that "The purpose of this study is to understand how people and their romantic partners cope with acute stress." Interested couples made an appointment to visit the laboratory.

Couples separately completed questionnaires that included the previously mentioned demographic information, the measure of pain catastrophizing (PCS), and the measure of both partners' perceived threat regarding pain that the participant was about to experience. Participants were then informed about which partner would undergo the cold pressor task, which was determined randomly by the research assistant flipping a coin. Both partners then watched a video of a previous participant undergoing the cold pressor task, which was designed to manipulate perceived threat about the cold pressor task. For this manipulation, couples were randomized to 1 of 2 experimental groups. Briefly, 1 condition was designed to elicit fear about the cold pressor task and the other condition served as a neutral prime. Couples were not told of their group assignment nor that there were different groups until the debriefing when all study tasks had been completed. Both partners completed measures of perceived threat, for the second time, after the video prime. After the second measure of threat was collected, couples briefly discussed the task and again rated their perceived threat for a final time. Whereas participants and observers in the high threat prime group experienced an increase in perceived threat, the effect of the prime did not persist. ${ }^{6}$ In the current study, perceived threat scores at the third administration were used for analysis, without consideration of threat group, because there were no group differences in perceived threat at this final administration. Also note that this perceived threat score was selected because it was the most proximal to the cold pressor task administration.

\section{Cold Pressor Task}

Before the cold pressor task began, participants were asked to wash their hands before placing 1 hand in the water basin. The experimenter explained the procedure, required the participant to repeat the whole procedure back to them, and answered any questions the participant might have regarding the task. No jewelry was worn on the hands or wrists during the task, and participants could not be chewing gum or eating food. Participants first submerged their hand for 1 minute in a

Table 2. Mean Participant and Observer Pain Ratings According to Time Point

SECONDS

\begin{tabular}{lcccccccc} 
& 10 & 20 & 30 & 40 & 60 & 80 & 100 & 120 \\
\hline Participant & $5.13(2.86)$ & $5.68(2.71)$ & $6.51(2.50)$ & $7.09(2.44)$ & $7.45(2.33)$ & $7.44(2.16)$ & $7.05(2.36)$ & $6.69(2.79)$ \\
Observer & $2.89(2.86)$ & $3.26(2.87)$ & $3.96(2.81)$ & $4.54(2.88)$ & $4.91(2.95)$ & $5.09(3.04)$ & $5.27(2.94)$ & $5.09(3.02)$ \\
Pain difference & $2.27(2.75)$ & $2.26(2.73)$ & $2.23(2.67)$ & $2.24(2.66)$ & $2.22(2.69)$ & $2.25(2.71)$ & $2.32(2.74)$ & $2.35(2.75)$ \\
\hline
\end{tabular}


bucket of room temperature water to ensure that baseline temperatures were equivalent across participants. Observers were escorted to an adjacent room where they were told they would be observing their partners completing the task through a live video feed and rating their partners' pain whenever a tone sounded. Observers could view participants from their hips up, including emitted facial expressions and upper body movements. Participants were asked to keep their hand still in the basin and submerged at the wrist. Participants were asked to remain seated for the duration that they were able to keep their hand submerged. The participant's hand was visible to them while submerged.

The cold pressor task was assembled using a Techne brand (Bibby Scientific Ltd, Burlington, NJ) flow dip cooler (model RU-200), thermoregulator (model TE10D), and stainless steel basin. Participants were instructed to place 1 hand into the steel basin. Water in the basin flowed through a flow dip cooler, which extracts heat. A thermoregulator circulated the water and controlled the temperature, which was set to $6^{\circ} \mathrm{C}$ $\left(43^{\circ} \mathrm{F}\right)$. Participants were also asked to fix their gaze on a piece of paper on the wall while completing the task. When a repeating tone sounded, participants and observers provided written ratings of the levels of pain intensity for the participant with their hand in the basin.

Participants were not told that the maximum time that their hand could be submerged was 2 minutes. Participants were permitted, however, to remove their hand if they could no longer withstand pain from the cold pressor. The number of participants who withdraw their hands during the cold pressor task is shown in Table 3. Also unknown to the participants and observers were the intervals at which the tones would prompt them to rate pain intensity. Observers rated their partner's pain intensity at the same time intervals as the participants undergoing the task. When the cold pressor task was completed, the couple was debriefed on the experiment and allowed to ask further questions.

\section{Results}

\section{Preliminary and Descriptive Analyses}

A total of 7 couples (5.22\%) were removed from the data set for missing data. Four dyads were removed because of 1 or both partners missing more than $10 \%$

Table 3. Number of Participants Who Had Withdrawn Their Hand From the Cold Pressor According to Time Point

\begin{tabular}{cc}
\hline $\begin{array}{c}\text { Time Interval, } \\
\text { SeCONDS }\end{array}$ & $\begin{array}{c}\text { Total Number OF Participants } \\
\text { With HaND WithDRAWN }\end{array}$ \\
\hline 10 & 0 \\
20 & 8 \\
30 & 15 \\
40 & 19 \\
60 & 30 \\
80 & 40 \\
100 & 44 \\
120 & 46 \\
\hline
\end{tabular}

of the items measuring pain anxiety (ie, pain catastrophizing and perceived threat). The remaining 3 couples were removed because of 1 or both partners missing $10 \%$ or more of the items on surveys assessing for potential covariates (ie, relationship satisfaction and empathy). Missing data analyses did not reveal systematic patterns of missing data. Thus, 127 couples were included in the analyses.

Correlations were conducted for descriptive purposes. A significant relationship was found between participant and observer perceived threat, $r_{127}=.22, P<.05$. Greater observer pain catastrophizing, however, was significantly related to greater observer empathy, $r_{127}=.26, P<.01$. No such relationship was found between participant pain catastrophizing and empathy. Finally, a significant relationship was detected between participant pain catastrophizing and participant perceived threat, $r_{127}=.21, P<.05$. Pain rating congruence was not significantly related to relationship satisfaction or empathy; thus, these potential covariates were not included in further analyses.

\section{Participant-Observer Pain Rating Congruence}

It was expected that observers would, on average, report lower pain ratings than those provided by the participants completing the cold pressor task. Multilevel modeling analyses were conducted because multiple ratings of pain congruence were available for each couple (ie, "pain difference" or congruence scores were nested within couples). That is, the dependent variable was the pain difference score which was calculated at each interval. Congruence scores were created by calculating the raw difference between the participant and observers' pain ratings at each time point. An absolute difference score was initially considered; however, an absolute difference measure obscures the pattern we found with observers underestimating participants most of the time. On average, observers significantly underestimated participant pain. Participants, on average, rated their pain 2.29 points higher than their observing partners on an 11-point scale, $b=2.29$, standard error $(\mathrm{SE})=.24, \mathrm{t}_{125.1}=9.49, P<.001$. The figures account for this trend and provide an average estimation for the entire group about the trends for pain congruence.

Pain rating congruence was also predicted to increase over the course of the task. In previous studies, individual pain ratings have followed a curvilinear trajectory. ${ }^{12,26,41}$ Thus, linear and quadratic effects of time were included in the multilevel model. A significant relationship was found between pain rating congruence and curvilinear time, $\mathrm{b}=-.0002$, $\mathrm{SE}=.0004, \mathrm{t}_{549.4}=-4.93, P<.001$ (see Fig 1). Congruence between pain ratings initially decreased (ie, "pain difference" between both partners" pain ratings became larger) before increasing over the 2 minute interval.

Further inspection of each partner's data separately shows that the curvilinear trajectory in congruence is due, in part, to different pain rating trajectories for 


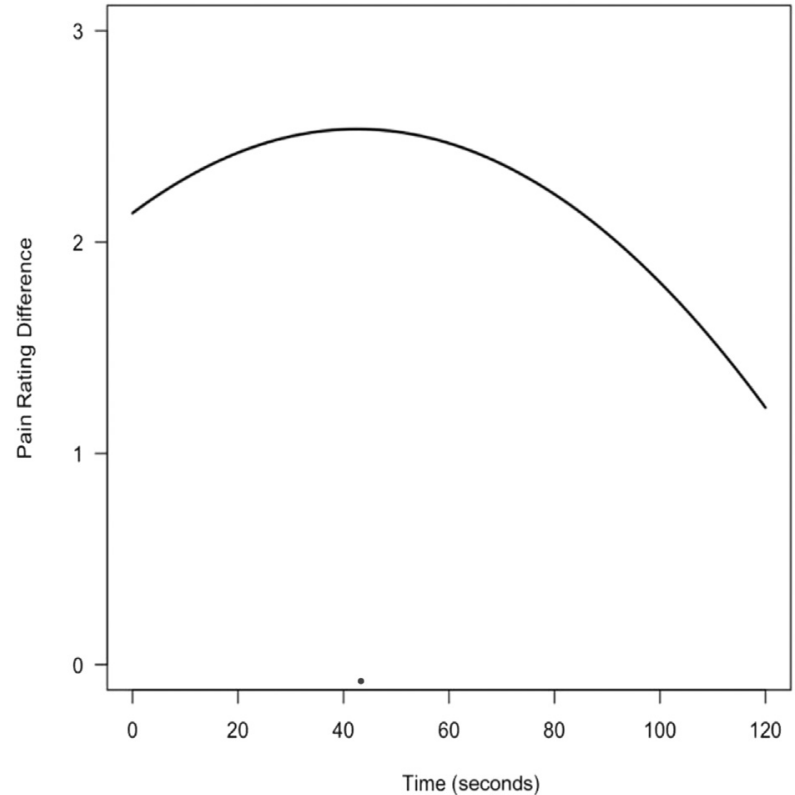

Figure 1. Pain rating congruence over the course of the task. Lower pain difference scores indicate greater congruence.

participants and observers. Multilevel modeling analyses showed a role (participant vs observer) according to quadratic time interaction $(b=-.0002$, SE $=.00005$, $\left.t_{1,000}=-4.88, P<.001\right)$. Further analyses of each partner's pain ratings over time showed significant quadratic effects of time (participant: $b=-.0006, S E=.00003$, $t_{590.5}=-20.99, P<.001 ;$ observer: $b=-.0004$, $\left.\mathrm{SE}=.00004, \mathrm{t}_{562.8}=-10.43, P<.001\right)$. Participant and observer pain rating trajectories are shown in Fig 2 . Although participants reported higher scores overall,

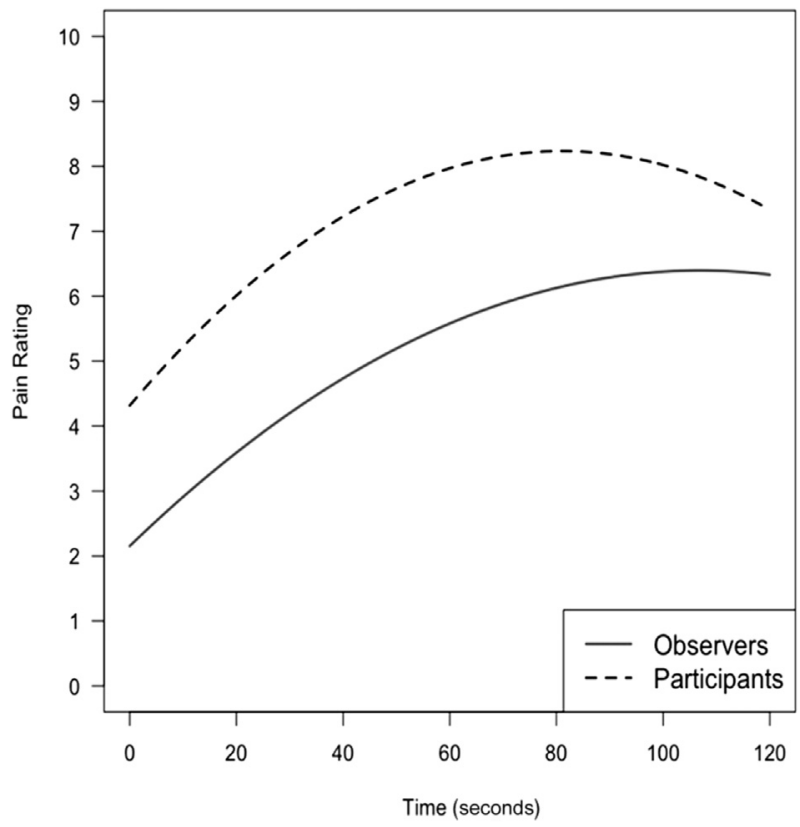

Figure 2. Participants' and observers' individual pain ratings over time. observers' reports became more similar to participants reports starting at the 80 -second mark of the task.

\section{Pain Anxiety and Congruence}

\section{Participants' Pain Anxiety}

Multilevel modeling analyses were again implemented to test if participant pain catastrophizing or perceived threat were related to pain rating congruence. Neither of the participants' indicators of pain anxiety was related to congruence on average (ie, the main effects of these variables were not significant). However, participant perceived threat interacted with the quadratic effect of time to influence congruence, $\mathrm{b}=.00001, \mathrm{SE}=.000007, \mathrm{t}_{690.9}=2.11, P=.03$. Fig 3 shows that pain rating congruence trajectories were different for participants reporting lower and higher perceived threat scores. At lower levels of threat, congruence followed a similar curvilinear trajectory as reported earlier (ie, slight decrease in congruence followed by greater congruence further along in the task). However, higher levels of perceived threat were related to a steady and steep increase in congruence throughout the cold pressor task. Participant pain catastrophizing was not related to congruence even when including the effect of time.

\section{Observer Pain Anxiety}

Neither observer perceived threat nor observer pain catastrophizing predicted congruence. The main effects of these 2 variables were not significant and neither were the interactions that included linear and quadratic time.

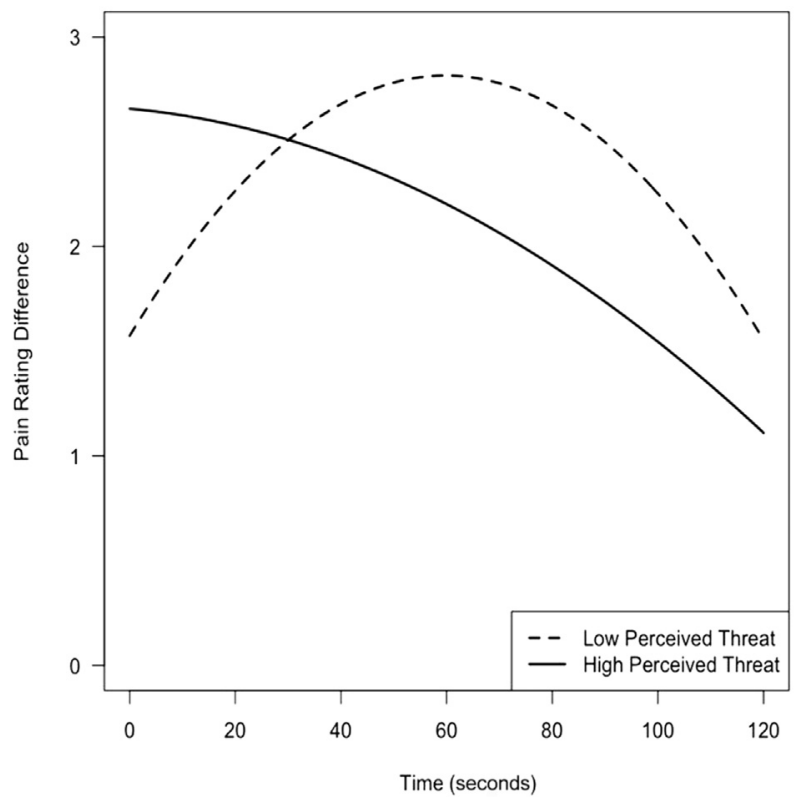

Figure 3. Pain rating congruence over time related to high and low perceived threat in the participant. Lower pain difference scores indicate greater congruence. Participants and observers considered as reporting high threat were +1 SD above the sample mean perceived threat score and participants and observers considered low threat were -1 SD. 

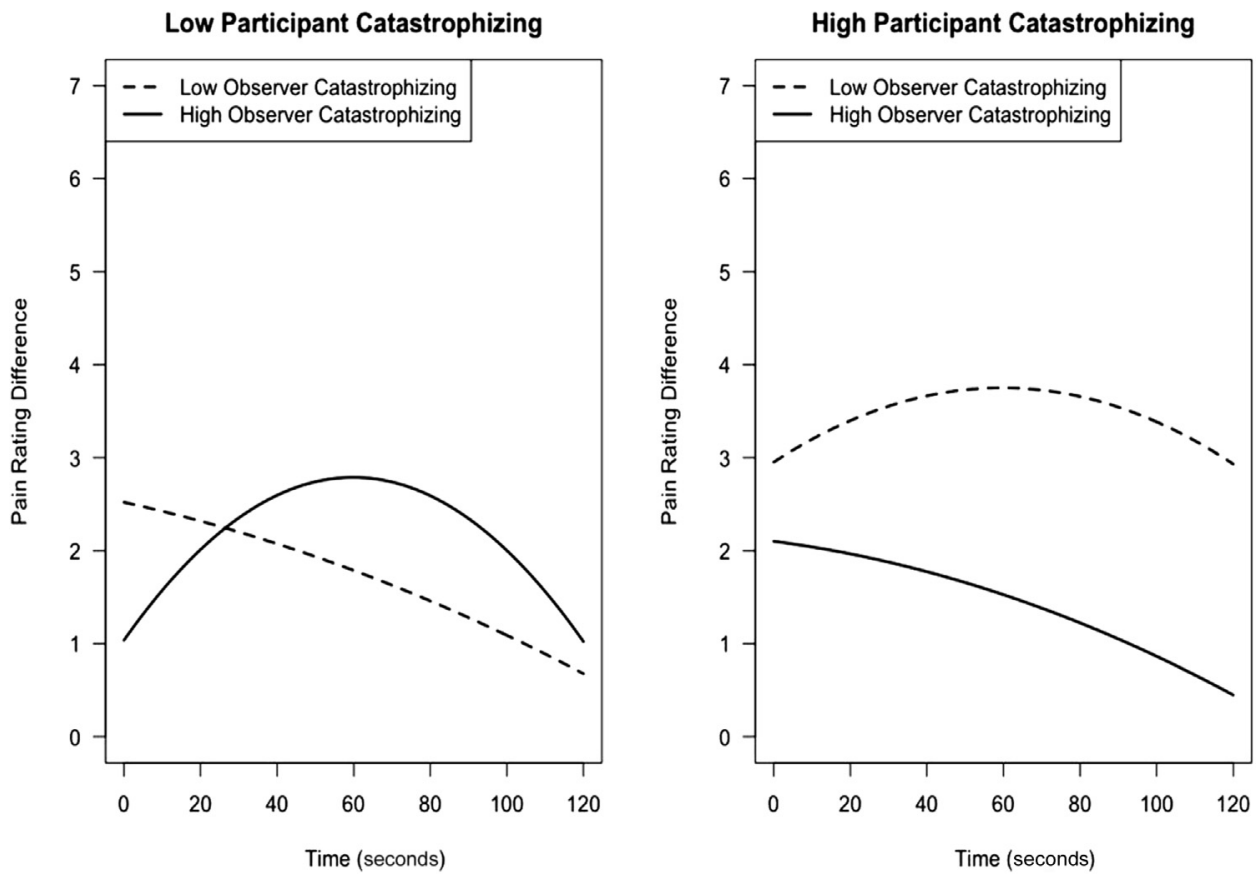

Figure 4. Interaction between baseline observer and participant pain catastrophizing on pain rating congruence over time. Lower pain difference scores indicate greater congruence. Participants and observers considered high catastrophizing were +1 SD above the sample mean pain catastrophizing score and participants and observers considered low catastrophizing were -1 SD.

\section{Participant and Observer Pain Anxiety Interactions}

Finally, multilevel modeling analyses were used to test for interactions between pain catastrophizing and perceived threat within and between partners. For participants and observers, one's own pain catastrophizing did not significantly interact with one's own perceived threat to predict congruence. No significant interactions between participant and observer perceived threat were found.

However, a significant interaction was detected between participant and observer pain catastrophizing over time in predicting congruence (see Fig 4), $\mathrm{b}=.000002, \mathrm{SE}=.0000006, \mathrm{t}_{708}=2.41, P=.02$. Among participants reporting lower levels of pain catastrophizing, greater observer catastrophizing was associated with initial increases in pain rating difference (ie, couples become more incongruent before becoming more similar near the end of the task). However, among participants reporting lower levels of pain catastrophizing, lower observer pain catastrophizing was associated with more rapid pain rating congruence. Similarly, among participants with higher levels of catastrophizing, greater observer catastrophizing was associated with a quick increase in pain rating congruence (ie, couples became steadily similar over time). Among participants with higher levels of catastrophizing, lower observer catastrophizing was associated with an initial decreased pain rating congruence (ie, couples gradually became more dissimilar in pain ratings until the middle of the task). In other words, mismatches in participantobserver catastrophizing scores appeared to result in pain rating differences becoming more incongruent dur- ing the task. Matching levels of pain catastrophizing appeared to result in greater and more rapid congruence over the course of the task.

\section{Discussion}

Pain empathy models suggest that observers develop a "sense of knowing" about another's pain, in part, by observation. However, previous research on pain congruence has focused predominantly on static measures of pain (ie, single assessments of pain ratings at rest), often on the basis of recall and not observational methods. Thus, it has been difficult to know how one's sense of knowing about another's pain may change over time, especially as a result of viewing a partner during painful tasks or activities. An aim of the current study was to assess and track pain rating congruence in a manner that could account for in-the-moment changes that may occur during a painful task. The current findings replicated existing work with clinical samples, which has reported that patient pain ratings are frequently underestimated by spouses, family members, and health care providers. $^{2-4,32,34}$ Consistent with the literature, participants in the present study assigned a higher rating to their own pain than their observing partners assigned to the participants. The current study also extended existing work by examining temporal changes in pain congruence. As expected, both partners' ratings became more similar over time. At the early stages of the task, partners became gradually dissimilar in their pain ratings, decreasing in congruence. However, by the end of the task, partners became more congruent. Greater congruence over time 
appeared to be due to observing partners "meeting" the participants in pain ratings, which supports the idea that the observers' knowledge of their partner's pain increased by viewing their partners engage in the task over time. Thus, congruence during the cold pressor task follows a dynamic course, one that was not observable in studies of static pain ratings. Further research is needed to see if a similar trajectory is observed during other types of painful tasks and during the course of activities for those with chronic pain.

Models of pain empathy have suggested that characteristics of observers and people with pain influence observers' sense of knowing about pain. ${ }^{13}$ Indeed, the findings of this study support this model by showing that pain anxiety in both partners was correlated with pain congruence. Pain catastrophizing and perceived threat were examined as correlates of interest because of the extensive research on pain anxiety and outcomes. For instance, pain catastrophizing is related to more intense pain in experimental and clinical studies, ${ }^{16,38,40}$ and perceived threat is associated with hypervigilance, negative physical responses to pain, and lower pain tolerance. ${ }^{23,28,40}$ Among participants, it was expected that pain catastrophizing and perceived threat would serve a communicative role and result in increased pain rating congruence. However, only participant perceived threat (ie, the participant's reported fear of the task before the task) interacted with time in predicting congruence. Couples in which the participants reported higher threat became more congruent over the task. Couples in which participants reported lower threat were more likely to report similar pain ratings at the onset of the task but became more dissimilar by the middle of the task. Notably, other dyadic studies investigating the effects of threat have also reported that pain appraisals influence the experience of pain. ${ }^{18}$ Future work could explore the extent to which expressed pain behavior may explain the rapid increase in congruence among couples in which participants report higher threat. $^{38}$

It was hypothesized that observers' pain catastrophizing or perceived threat would predict a greater defensive distancing response, resulting in less congruence. This hypothesis was largely not supported as observers' pain anxiety did not predict congruence (except as it interacted with participants' anxiety). Yet, in a study of parent-child dyads, parental catastrophizing was reported to be related to increased congruence, perhaps because parents who catastrophized were more vigilant about pain cues. ${ }^{15}$ It is possible that the study's design (ie, participant and observers were already physically distant by being placed in separate rooms) prevented a complete test of the defensive distancing hypothesis. Perhaps, it would be more likely to find evidence of defensive distancing in a design in which both partners were present in the same room or with chronic pain samples, for whom the threat of pain would be more distressing to observers. Continued exploration is needed to explore the mechanisms through which observer anxiety may contribute to incongruence.
Participant and observer pain anxiety interacted to predict congruence in one instance: pain catastrophizing. Pain rating congruence was accelerated among couples in which observers and participants either both reported higher levels or both reported lower levels of pain catastrophizing. For couples who were mismatched in pain catastrophizing (ie, one reported high levels and the other low levels), congruence was more likely to follow a trajectory of increased dissimilarity or incongruence before returning to near baseline levels of congruence. This finding runs counter to the assumption that anxiety in both partners may increase avoidance and decrease congruence. Perhaps, couples with similar trait-like pain anxiety may be more attuned to each other's experiences, enhancing the observers' sense of knowing about their partners' pain. Indeed, similarities between partners on traits such as values, warmth, dominance, and activity are related to increased closeness and relationship satisfaction. ${ }^{11,27,30}$

Note that observers' empathic feelings toward the participant were not associated with pain congruence in this study. Although initially surprising, it is possible that this finding is because of different conceptualizations and measurements of empathy. In this study, the measure of empathy was "empathic concern," or feelings of empathy. However, pain congruence may be tapping into a dimension of empathy that is more cognitive in nature. Indeed, empathy has emotional, cognitive, and behavioral components. ${ }^{8,10,13}$ Similar small correlations among empathy variables have been reported in social psychology research, ${ }^{1}$ and in pain research. ${ }^{17,25}$ Thus, whereas pain congruence may be a reflection of the empathy process, small correlations with other aspects of empathy are to be expected.

\section{Limitations}

Although the results of the present study extend our understanding of the time course and correlates of pain congruence, some limitations must be considered. In the current study, the observer was not present in the room with the participant undergoing the cold pressor task. An advantage of this strategy was that it eliminated the potential for interference from the observer, which would have prevented a "clean" examination of congruence. Because other studies have included both partners present in the same room while one partner undergoes a painful task, ${ }^{5}$ it may be useful to examine how partner presence may alter the trajectory of pain congruence, specifically its influence on the effects of observer anxiety previously mentioned.

The data were collected from an undergraduate, nonclinical population. Research is needed to test whether the findings are replicable in longer-term relationships, relationships in which 1 partner has a chronic condition, and in nonromantic relationships (eg, patient-provider congruence) samples. This study was also limited to a 2minute time interval, which may not reflect the time course of pain for individuals who suffer from chronic pain or are engaging in activities of longer duration. Finally, codeable video recordings were not available for 
this study. Researchers are encouraged to use this paradigm and capture high-quality video to test the hypothesis that pain anxiety may contribute to pain behaviors that observers may use to estimate the pain of their partners. Furthermore, congruence trajectories in other forms of experimentally-induced pain as well as clinical acute and chronic pain should be explored.

\section{Conclusions}

In the real world, observers develop a sense of knowing about their partners' pain by observing their loved ones engaging in daily life tasks. Therefore, it is necessary that researchers assess pain congruence using methods that account for the changing nature of pain during painful tasks. In the current study, the cold pressor task was used as an experimental acute pain task to show that pain ratings and congruence scores do indeed change during the course of a painful task. It is possible that a similar approach could be used to assess pain congruence among patients and observers, including health care providers and loved ones, during exercise or other activities to better understand the manner in which observers' sense of knowing about another's pain is developed. Clinically, such pain rating activities may be used as a basis for conversations about pain communication to enlighten

\section{References}

1. Batson CD, Fultz J, Schoenrade PA: Distress and empathy: Two qualitatively distinct vicarious emotions with different motivational consequences. J Pers 55: 19-39, 1987

2. Cano A, Johansen A, Franz A: Multilevel analysis of couple congruence on pain, interference, and disability. Pain 118:369-379, 2005

3. Cano A, Johansen A, Geisser M: Spousal congruence on disability, pain, and spouse responses to pain. Pain 109: 258-265, 2004

4. Clipp EC, George LK: Patients with cancer and their spouse caregivers: Perceptions of the illness experience. Cancer 69:1074-1079, 1992

5. Coan JA, Schaefer HS, Davidson RJ: Lending a hand: Social regulation of the neural response to threat. Psychol Sci 17: 1032-1039, 2006

6. Corley AM, Cano A, Goubert L, Vlaeyen JW, Wurm LH: Global and situational relationship satisfaction moderate the effect of threat on pain in couples. Pain Med 17: 1664-1675, 2016

7. Davis MH: A multidimensional approach to individual differences in empathy. JSAS Catalog of Selected Documents in Psychology 10:85, 1980

8. Davis MH: Empathy: A social psychological approach. Boulder, CO, Westview Press, 1996

9. Eccleston C, Crombez G: Pain demands attention: A cognitive-affective model of the interruptive function of pain. Psychol Bull 125:356-366, 1999

10. Eisenberg $N$, Strayer J: Critical issues in the study of empathy. New York, NY, Cambridge University Press, 1987 people with pain about how their pain anxiety may affect their communication about pain to others and how observers interpret and respond to pain.

Researchers are encouraged to examine pain anxiety (pain catastrophizing and perceived threat) as well as other emotional states (eg, depressed mood), other components of pain anxiety (eg, physiological reactions, avoidance behaviors, and pain beliefs), ${ }^{20}$ and behaviors (eg, solicitous responses, empathic behaviors) as correlates of congruence. The current study contributes to the pain empathy literature by providing pain researchers a novel approach of assessing pain rating congruence that uses existing methodologies and analytic tools: a standardized experimental pain task and multilevel modeling. In addition, the knowledge that time and pain anxiety in both partners can alter the course of pain rating congruence provides support for pain empathy models and suggests that future researchers should examine the consequences of enhanced congruence and how congruence may be enhanced by working with both partners.

Ultimately, a better understanding of pain rating congruence can lead researchers to investigate the extent to which it is associated with health and wellbeing among people with pain and their loved ones.

11. Gaunt R: Couple similarity and marital satisfaction: Are similar spouses happier? J Pers 74:1401-1420, 2006

12. Geisser ME, Robinson M, Keefe F, Weiner M: Catastrophizing depression and the sensory, affective and evaluative aspects of chronic pain. Pain 59:79-83, 1993

13. Goubert L, Craig K, Vervoort T, Morley S, Sullivan M, Williams A, Cano A, Crombez G: Facing others in pain: The effects of empathy. Pain 118:285-288, 2005

14. Goubert L, Eccleston C, Vervoort $T$, Jordan $A$, Crombez G: Parental catastrophizing about their child's pain. The parent version of the Pain Catastrophizing Scale (PCS-P): A preliminary validation. Pain 123:254-263, 2006

15. Goubert L, Vervoort T, Cano A, Crombez G: Catastrophizing about their children's pain is related to higher parent-child congruency in pain ratings: An experimental investigation. Eur J Pain 13:196-201, 2009

16. Goubert L, Vervoort T, Sullivan MJ, Verhoeven K, Crombez G: Parental emotional responses to their child's pain: The role of dispositional empathy and catastrophizing about their child's pain. J Pain 9:272-279, 2008

17. Issner JB, Cano A, Leonard MT, Williams AM: How do I empathize with you? Let me count the ways: Relations between facets of pain-related empathy. J Pain 13:167-175, 2012

18. Jackson T, Huang X, Chen H, Phillips H: Effects of threatening information on interpersonal responses to pain. Eur J Pain 13:431-438, 2009

19. Jaremka LM, Bunyan DP, Collins NL, Sherman DK: Reducing defensive distancing: Self-affirmation and risk regulation in response to relationship threats. J Exp Soc Psychol 47:264-268, 2011 
20. Jensen MP, Turner JA, Romano JM: Chronic pain coping measures: Individual vs. composite scores. Pain 51:273-280, 1992

21. Kain Z, Mayes L, Caldwell-Andrews A, Karas D, McClain B: Preoperative anxiety, postoperative pain, and behavioral recovery in young children undergoing surgery. Pediatrics 118:651-658, 2006

22. Kain Z, Sevarino F, Alexander G, Pincus S, Mayes L: Preoperative anxiety and postoperative pain in women undergoing hysterectomy. J Psychosom Res 49:417-422, 2000

23. Kirwilliam SS, Derbyshire WG: Increased bias to report heat or pain following emotional priming of pain-related fear. Pain 137:60-65, 2008

24. Leeuw M, Goossens M, Linton S, Crombez G, Boersma K, Vlaeyen J: The fear-avoidance model of musculoskeletal pain: Current state of scientific evidence. J Behav Med 30:77-94, 2007

25. Leonard MT, Issner JB, Cano A, Williams AM: Correlates of spousal empathic accuracy for pain-related thoughts and feelings. Clin J Pain 29:324-333, 2013

26. Leong L, Cano A, Wurm L, Lumley M, Corley A: A perspective taking manipulation leads to greater empathy and less pain during the cold pressor task. J Pain 16:1176-1185, 2015

27. Markey PM, Markey CN: Romantic ideals, romantic obtainment, and relationship experiences: The complementarity of interpersonal traits among romantic partners. J Soc Person Rel 24:517-533, 2007

28. Meagher M, Arnau R, Rhudy J: Pain and emotion: Effects of affective picture modulation. Psychosom Med 63:79-90, 2001

29. Miaskowski C, Zimmer EF, Barrett KM, Dibble SL, Wallhagen M: Differences in patients' and family caregivers' perceptions of the pain experience influence patient and caregiver outcomes. Pain 72:217-226, 1997

30. Pickford JH, Signori El, Rempel H: Similar or related personality traits as a factor in marital happiness. J Marriage Fam 28:190-192, 1966

31. Pyszczynski T, Greenberg J, Solomon S, Cather C, Gat I, Sideris J: Defensive distancing from victims of serious illness: The role of delay. Personal Soc Psychol Bull 21:13-20, 1995

32. Riemsma R, Taal E, Wiegman O, Rasker JJ, Bruyn GA, van Paassen HC: Problematic and positive support in relation to depression in people with rheumatoid arthritis. J Health Psychol 5:221-230, 2000

33. Sjöling M, Nordahl G, Olofsson N, Asplund K: The impact of preoperative information on state anxiety, postoperative pain and satisfaction with pain management. Pat Educ Couns 51:169-176, 2003

34. Solomon P: Congruence between health professionals' and patients' pain ratings: A review of the literature. Scand J Caring Sci 15:174-180, 2001

35. Sullivan MJ, Adams H, Sullivan ME: Communicative dimensions of pain catastrophizing: Social cueing effects on pain behaviour and coping. Pain 107:220-226, 2004

36. Sullivan MJ, Bishop S, Pivik J: The pain catastrophizing scale: Development and validation. Psychol Assess 7: 432-524, 1995

37. Sullivan MJ, Martel MO, Tripp D, Savard A, Crombez G: The relation between catastrophizing and the communication of pain experience. Pain 122: $282-288,2006$

38. Sullivan MJ, Thorn B, Haythornthwaite JA, Keefe F, Martin M, Bradley LA, Lefebvre JC: Theoretical perspectives on the relation between catastrophizing and pain. Clin J Pain 17:52-64, 2001

39. Vervoort T, Caes L, Crombez G, Koster E, Van Damme S, Dewitte M, Goubert L: Parental catastrophizing about children's pain and selective attention to varying levels of facial expression of pain in children: A dot-probe study. Pain 152: 1751-1757, 2011

40. Vlaeyen JW, Linton SJ: Fear-avoidance and its consequences in chronic musculoskeletal pain: A state of the art. Pain 85:317-332, 2000

41. Wolf S, Hardy JD: Studies on pain. Observations on pain due to local cooling and on factors involved in the "cold pressor" effect. J Clin Invest 20:521, 1941 